\title{
Postnatal development of the endbulb of Held in congenitally deaf cats
}

\author{
Christa A. Baker ${ }^{1,2}$, Karen L. Montey ${ }^{1,3}$, Tan Pongstaporn' and David K. Ryugo ${ }^{1,4,5 *}$ \\ 1 Department of Otolaryngology, Johns Hopkins University, Baltimore, MD, USA \\ 2 Program in Neuroscience, Division of Biology and Biomedical Sciences, Washington University, St. Louis, MO, USA \\ ${ }^{3}$ Department of Biology, University of Maryland, College Park, MD, USA \\ ${ }^{4}$ Department of Neuroscience, Johns Hopkins University, Baltimore, MD, USA \\ ${ }^{5}$ Garvan Institute of Medical Research, Darlinghurst, NSW, Australia
}

\section{Edited by:}

Enrique Saldaña, Universidad de Salamanca, Spain

\section{Reviewed by:}

Enrico Mugnaini, Northwestern University, USA

Nell B. Cant, Duke University, USA

\section{${ }^{*}$ Correspondence:}

David K. Ryugo, Department of Otolaryngology, Johns Hopkins University, 720 Rutland Ave., 510 Traylor Bldg., Baltimore, MD 21205, USA.

e-mail:dryugo@jhu.edu
The endbulbs of Held are formed by the ascending branches of myelinated auditory nerve fibers and represent one of the largest synaptic endings in the brain. Normally, these endings are highly branched and each can form up to 1000 dome-shaped synapses. The deaf white cat is a model of congenital deafness involving a type of cochleosaccular degeneration that mimics the Scheibe deformity in humans. Endbulbs of mature deaf white cats exhibit reduced branching, hypertrophy of postsynaptic densities (PSDs), and changes in synaptic vesicle density. Because cats are essentially deaf at birth, we sought to determine if the progression of brain abnormalities was linked in time to the failure of normal hearing development. The rationale was that the lack of sound-evoked activity would trigger pathologic change in deaf kittens. The cochleae of deaf cats did not exhibit abnormal morphology at birth. After the first postnatal week, however, the presence of a collapsed scala media signaled the difference between deaf and hearing cats. By working backwards in age, endbulbs of deaf cats expressed flattened and elongated PSDs and increased synaptic vesicle density as compared to normal endbulbs. These differences are present at birth in some white kittens, presaging deafness despite their normal cochlear histology. We speculate that hearing pathology is signaled by a perinatal loss of spontaneous bursting activity in auditory nerve fibers or perhaps by some factor released by hair cell synapses before obliteration of the organ of Corti.

Keywords: auditory nerve, cochlear nucleus, hearing synapse, ultrastructure

\section{INTRODUCTION}

The endbulb of Held is a large auditory nerve ending which makes synaptic contact with spherical bushy cells (SBCs) in the anteroventral cochlear nucleus (AVCN). It represents one of the largest endings in the brain and has been implicated in the precise transmission of timing information from auditory stimuli (Pfeiffer, 1966a,b; Molnar and Pfeiffer, 1968; Ryugo and Fekete, 1982; Carr and Konishi, 1990; Smith et al., 1993; Koppl, 1994; Koppl and Carr, 1997). Detailed study of endbulb development in cats revealed that the most significant changes in structural features occur over the first twenty postnatal days (Ryugo and Fekete, 1982; Ryugo et al., 2006). During this time, the spoon-shaped endbulb elaborates into a highly branched arborization, intermembraneous cisternae form, postsynaptic densities (PSDs) elongate, and the concentration of synaptic vesicles increases. These morphological changes in the endbulb are correlated in time to changes in physiological properties of the parent auditory nerve fiber. Following this rapid postnatal development, endbulb structure and auditory nerve fiber response properties sustain a slow maturation until 90-days postnatal (Ryugo and Fekete, 1982).

Congenital deafness is associated with morphological changes in endbulb structure including reduced branching, hypertrophy of PSDs, and variations in synaptic vesicle density (Ryugo et al., 1997, 1998, 2005; Limb and Ryugo, 2000; Lee et al., 2003). The deaf white cat is a model of congenital deafness involving a type of cochleosaccular degeneration which mimics the Scheibe deformity in humans (Scheibe, 1892, 1895; Bosher and Hallpike, 1965, 1967; Deol, 1970; Suga and Hattler, 1970; Mair, 1973; Brighton et al., 1991). Unlike humans, however, cats are altricial animals whose ear canals are closed at birth. By postnatal day 30 , the ear canal opens and kittens are considered fully hearing. The time course of canal opening is the same for deaf white kittens and normal hearing kittens (Ryugo et al., 2003).

Because cats are deaf at birth, we sought to determine whether the emergence of abnormalities at the endbulb of Held synapse in deaf white cats coincided in time with the development of hearing in normal cats. The rationale was that the lack of soundevoked activity would trigger pathologic change in deaf kittens. To this end, we examined the ultrastructure of endbulbs in an age-graded series of deaf kittens and compared the results with those previously reported for normal hearing kittens (Ryugo et al., 2006).

\section{MATERIALS AND METHODS SUBJECTS}

Forty-nine cats contributed new data that were used for this report (Table 1). Structural data were collected from an age-graded series of congenitally deaf cats of either sex that ranged in postnatal age (PN) from newborn ( $\mathrm{PN}-0)$ to adult. The auditory nerve endings in the cochlear nucleus of two kittens were analyzed at each of the 
Table 1 | Subjects.

\begin{tabular}{|c|c|c|c|c|c|c|c|c|}
\hline \multirow{3}{*}{ Subject age } & \multicolumn{4}{|c|}{ White cats } & \multicolumn{4}{|c|}{ Pigmented cats } \\
\hline & \multirow[t]{2}{*}{$\begin{array}{l}\text { Number of } \\
\text { subjects }\end{array}$} & \multicolumn{2}{|c|}{$\begin{array}{l}\text { Cochleae } \\
\text { analyzed }\end{array}$} & \multirow[t]{2}{*}{$\begin{array}{l}\text { Brains } \\
\text { analyzed }\end{array}$} & \multirow[t]{2}{*}{$\begin{array}{l}\text { Number of } \\
\text { subjects }\end{array}$} & \multicolumn{2}{|c|}{$\begin{array}{l}\text { Cochleae } \\
\text { analyzed }\end{array}$} & \multirow[t]{2}{*}{$\begin{array}{l}\text { Brains } \\
\text { analyzed }\end{array}$} \\
\hline & & LM & EM & & & LM & EM & \\
\hline 0 days & 23 & 20 & 3 & 7 & $2^{*}+3$ & $2^{*}+2$ & 1 & $2^{*}+1$ \\
\hline 5 days & 2 & 2 & & 2 & $2^{*}$ & $2^{*}$ & & $2^{*}$ \\
\hline 10 days & 2 & 2 & & 2 & $2^{*}$ & $2^{*}$ & & $2^{*}$ \\
\hline 20 days & 2 & 2 & & 2 & $2^{*}$ & $2^{*}$ & & $2^{*}$ \\
\hline 30 days & 2 & 2 & & 2 & $2^{*}$ & $2^{*}$ & & $2^{*}$ \\
\hline 60 days & 2 & 2 & & 2 & $2^{*}$ & $2^{*}$ & & $2^{*}$ \\
\hline 90 days & 2 & 2 & & 2 & $2^{*}$ & $2^{*}$ & & $2^{*}$ \\
\hline 120 days & 2 & 2 & & 2 & $2^{*}$ & $2^{*}$ & & $2^{*}$ \\
\hline 150 days & 2 & 2 & & 2 & $2^{*}$ & $2^{*}$ & & $2^{*}$ \\
\hline 180 days & 2 & 2 & & 2 & $2^{*}$ & $2^{*}$ & & $2^{*}$ \\
\hline Adult & 5 & 5 & & 5 & $5^{*}$ & $5^{*}$ & & $5^{*}$ \\
\hline
\end{tabular}

*Pigmented kitten data are from Ryugo et al. (2006); they are included in Figures 5, 6, 7, 12, and 13 for comparison purposes.

following postnatal ages: $5,10,20,30,60,90,120,150$, and 180 days. In addition, five adult cats 240 days of age or older were used due to unexpected variability of the features measured for analysis. A total of 26 newborn kittens contributed brain and cochlear tissue. Twenty white PN-0 kittens and four pigmented PN-0 kittens were used to examine inner ear morphology using light microscopy. Three more white newborns and one pigmented newborn were prepared for electron microscopic examination of inner hair cell synapses onto spiral ganglia. All animals with the exception of three pigmented kittens and three pigmented adults were from our colony of white cats with a family history of congenital deafness.

For kittens 5 days of age or older, criteria for inclusion in this study consisted of: (1) bilateral profound deafness as determined by auditory brainstem responses (ABRs) and/or cochlear histology that documented the absence of an organ of Corti, and (2) good ultrastructural appearance of brain tissue when viewed with an electron microscope. Criteria for the inclusion of newborn kittens were healthy appearance at birth and adequately fixed tissue for examination with light and electron microscopy. Standard ABRs were recorded from animals 30-days postnatal and older. An animal was determined to be deaf after registering no response to clicks or noise bursts that were presented up to $100 \mathrm{~dB}$ SPL. All procedures were in accordance with NIH guidelines and were approved by the Animal Care and Use Committee of the Johns Hopkins University.

\section{HISTOLOGICAL PREPARATION}

Animals were deeply anesthetized with sodium pentobarbital $(75 \mathrm{mg} / \mathrm{kg}, \mathrm{IP})$ and when unresponsive to corneal stimulation were perfused transcardially with $0.12 \mathrm{MPBS}$ with $0.1 \% \mathrm{NaNO}_{2}$ followed by $2 \%$ paraformaldehyde $/ 2 \%$ glutaraldehyde. Brains were allowed to post-fix overnight at $4{ }^{\circ} \mathrm{C}$ in the same fixative. The brainstem was then embedded in bovine serum albumin gel hardened with glutaraldehyde. Coronal sections through the cochlear nuclei were cut using a Vibratome at a thickness of $50 \mu \mathrm{m}$ for light microscopic analysis and $75 \mu \mathrm{m}$ for electron microscopic analysis. Sections destined for light microscopy were mounted on glass slides, stained with cresyl violet, cleared with xylenes, and coverslipped with Permount. Sections for electron microscopy were en bloc stained with $1 \% \mathrm{OsO}_{4}$, incubated in uranyl acetate overnight, dehydrated, and embedded in PolyBed 812 resin between sheets of Aclar. After polymerization, relevant portions of the AVCN were cut out and embedded in BEEM capsules. Ultrathin sections were collected on Formvar-coated slotted grids and examined in a Hitachi H-7600 electron microscope.

Immediately after transcardial perfusion, the cochleae of each animal were perfused with the same fixative and dissected out of the temporal bone. Cochleae meant for electron microscopic analysis were also flushed with $1 \% \mathrm{OsO}_{4}$. After decalcification with $0.1 \mathrm{M}$ ethylenediaminetetraacetic acid (EDTA), cochleae were dehydrated in increasing concentrations of alcohols, embedded in Araldite, and cut on a rotary microtome at $20 \mu \mathrm{m}$. Sections through the mid-modiolar plane were mounted on glass slides, stained with toluidine blue, cleared with xylenes, and coverslipped with Permount for viewing in a light microscope. Mid-modiolar sections through cochleae intended for electron microscopy were mounted in Epon and processed by the same method as described for brainstem sections.

\section{DATA ANALYSIS}

The histologic appearance of the cochlea was used to identify deaf kittens less than 30-days old. Deafness in our colony of white cats manifests as one of three pathologies: (1) a collapsed Reissner's membrane and obliteration of the scala media, (2) excessive epithelial growth on Reissner's membrane and within the scala media and scala tympani resulting in a spongiform appearance, or (3) a combination of spongiform growth in the apex of the cochlea and collapsed Reissner's membrane in the base (Ryugo et al., 2003). Light microscopic examination of the cochleae from 20 PN- 0 white kittens revealed only one kitten with pathologic histology indicative 
of deafness. This newborn kitten had spongiform growth in both cochleae. The rest of the newborn kittens exhibited normal cochlear histology in agreement with previous observations on newborn white cats (Mair, 1973). For synapse analysis, we selected six PN-0 white kittens from a breeding pair that only produced deaf offspring. These seven newborn kittens, one with and six without obvious cochlear pathology, represented newborn kittens for this study.

Electron micrographs of endbulbs of Held were subject to morphometric analyses described previously (Ryugo et al., 2006). Briefly, measurements of endbulb and mitochondrial area, PSD and apposition lengths, and number of PSDs, puncta adherentia, cisternae, SBC inclusions, large dense-core vesicles, and synaptic vesicles were collected using Adobe Photoshop $v 7$ and NIH ImageJ v1.37. For synaptic vesicle density measurements, the area of the endbulb within $0.5 \mu \mathrm{m}$ of each PSD was defined and measured. The number of synaptic vesicles located within this region was then divided by the area of the region to yield synaptic vesicle density. Quantitative values are presented in the text as mean \pm standard deviation, whereas in the figures they are given as mean \pm standard error of the mean.

A minimum of eight endings was randomly selected from each animal, resulting in a total of 244 endbulb profiles. These data were compared to those of normal hearing cats (Ryugo et al., 2006), with the exception of synaptic vesicle density and large dense-core vesicle counts. Given the variability in shape of synaptic vesicles in electron micrographs even within the same ending, one observer recounted synaptic vesicles from normal animals. This step was necessary in order to allow direct comparison between synaptic vesicle density measurements from normal hearing and deaf cats. The recount changed the absolute values previously reported but the results remained qualitatively similar and the values were not statistically different. Since the other morphological features of endbulbs are readily identifiable, no additional re-analysis of normal data was performed. The quantification of large dense-core vesicles provided in this study was not previously reported for normal hearing animals. For the micrographs analyzed and presented here, only brightness and contrast were adjusted in Photoshop.

\section{RESULTS \\ AGES 0-10 DAYS \\ Cochleae}

At birth, light microscopic cochlear histology is similar in all pigmented $(n=4)$ and all but one white kitten $(n=20)$ studied. The cochleae of both cohorts (with the one mentioned exception) exhibit an intact Reissner's membrane, healthy stria vascularis, and a full complement of inner and outer hair cells (Figure 1, top). The first noticeable sign of degeneration is present at 5 days in white kittens, with Reissner's membrane beginning to collapse onto the tectorial membrane (Figure 1, middle). Inner and outer hair cells are still visible. By 10 days, however, Reissner's membrane has completely collapsed and obliterated the scala media. The organ of Corti deteriorates and hair cells are no longer distinguishable in white kittens (Figure 1, bottom). Sometimes unidentifiable cells occupy the site where the organ of Corti would normally reside, but they do not have apical tufts of stereocilia that would identify them as hair cells and it is not clear if they are residual supporting cells.
Mair (1973) reported the first sign of cochlear degeneration in deaf white kittens to be a wrinkling of Reissner's membrane. We found this feature unreliable as a harbinger of deafness because pigmented and white kittens exhibited considerable variations in Reissner's membrane, from being perfectly straight to undulating to bowed-out as in the case of hydrops (Figure 1). Some of the irregularity could be due to non-uniform fixation conditions. Examination of cochleae from newborn white kittens revealed only one with obvious pathologic morphology when viewed under a light microscope. This $\mathrm{PN}-0$ kitten had spongiform growth in both cochleae (see Ryugo et al., 2003). Three other newborn kittens from genetically dominant deaf parents provided cochleae with adequate preservation where normal synapses could be observed between the inner hair cell and afferent ending in an electron microscope.

\section{Endbulbs}

The newborn kitten with spongiform cochlear pathology was a clear case for deafness at birth. Epithelial cells that lined the cochlear duct and the basilar membrane were hypertrophied and there was no evidence for inner or outer hair cells. Endbulbs from this cat exhibited PSDs that were on average longer $(0.291 \pm 0.148 \mu \mathrm{m}, n=50$ PSDs $)$ than those of newborn pigmented kittens $(0.208 \pm 0.151 \mu \mathrm{m}, n=242$ PSDs $)$. The other six PN-0 white kittens also displayed abnormally long PSDs (mean $=0.365 \pm 0.271 \mu \mathrm{m}, n=144$ PSDs). Collectively, these newborn white kittens had on average significantly larger PSDs $(p<0.005$, Kruskal-Wallis Test) when compared to those of pigmented kittens destined to develop normal hearing. Therefore, we selected one of these newborn white kittens with large PSDs, in addition to the kitten with spongiform cochleae, for morphometric endbulb analysis.

The endbulb profile in newborn deaf animals is large in area and is considerably interdigitated with the SBC, as indicated by a highly irregular membrane and the presence of SBC "inclusions" within the endbulb (Figures 2 and 3). These inclusions are known to arise from the cell body as short filopodia or somatic spines as determined by reconstruction through serial sections. To quantify the extent of the interdigitation, the length of the straight-line segment of the endbulb-SBC apposition was divided by the length of the "wavy" apposition (see figure 1 of Ryugo et al., 2006). This ratio is called the apposition form factor. An apposition form factor of 1 indicates a perfectly straight apposition, whereas progressively smaller ratios denote increasingly more convoluted membrane appositions.

During the first ten postnatal days, the endbulb membrane abutting the SBC becomes more regular (apposition form factor approaches 1) and SBC inclusions disappear (Figures 4 and 5) in profiles from both cohorts. Endbulb profile area shrinks substantially as does the associated apposition length (Figure 5). This change is consistent with the developmental process whereby large components of the endbulb transform into progressively smaller swellings and finer fibers by sequential branching (Ryugo and Fekete, 1982; Limb and Ryugo, 2000). The number of puncta adherentia remains steady at about three per profile over this period (Figure 6A) in both pigmented and white kittens.

PSDs of deaf kittens steadily increase in length from $0.309 \pm 0.212 \mu \mathrm{m}$ at birth to $0.376 \pm 0.176 \mu \mathrm{m}$ at PN-10 (Figure 6C). The number of PSDs on endings of deaf subjects, however, is 


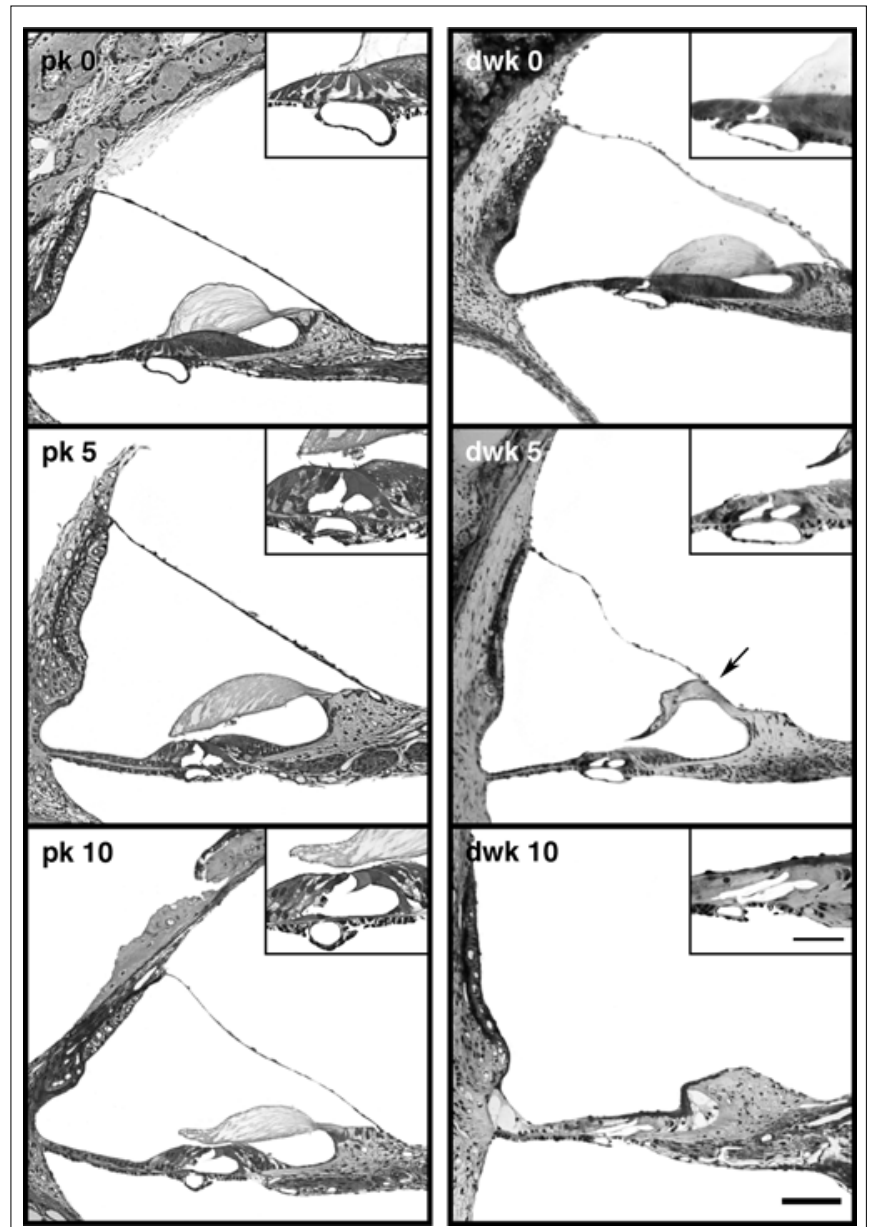

FIGURE 1 | Light micrographs of mid-modiolar cochlear sections from pigmented kittens (pk, left column) and deaf white kittens (dwk, right column). At day 0 (top row), the cochleae of white and pigmented kittens are similar in appearance. Reissner's membrane and inner and outer hair cells (inset) are intact. At postnatal day 5 (middle row), the first sign of cochlear degeneration is seen in white kittens as Reissner's membrane begins its collapse onto the tectorial membrane (arrow). By postnatal day 10 (bottom row), Reissner's membrane has fallen completely, obliterating the scala media and destroying the organ of Corti. Hair cells are no longer distinguishable in the damaged organ of Corti (inset). Scale bar equals $100 \mu \mathrm{m}$ and $50 \mu \mathrm{m}$ in the inset.

reduced from four PSDs per profile at PN-0 to three at PN-10 (Figure 6B). The number of large dense-core vesicles decreases from 1 to 2 per profile in newborn deaf kittens to an average of less than 1 at PN-10 (Figure 7E). Synaptic vesicle density seemed to be the most variable parameter both within and across animals. This value fluctuates between 50 and 100 vesicles $/ \mu \mathrm{m}^{2}$ in endings from deaf cats (Figure 7C). If synaptic vesicle number is influenced by the amount of activity in the fiber (e.g., Murthy et al., 2001), then events immediately preceding fixation could be relevant and might account for some of these differences.

Although average mitochondria size remains relatively constant at $0.077 \pm 0.052 \mu \mathrm{m}^{2}$ (Figure $7 \mathrm{~A}$ ), the proportion of profile area occupied by mitochondria increases $(9.1 \pm 6.5 \%$ to $11.7 \pm 5.7 \%$,

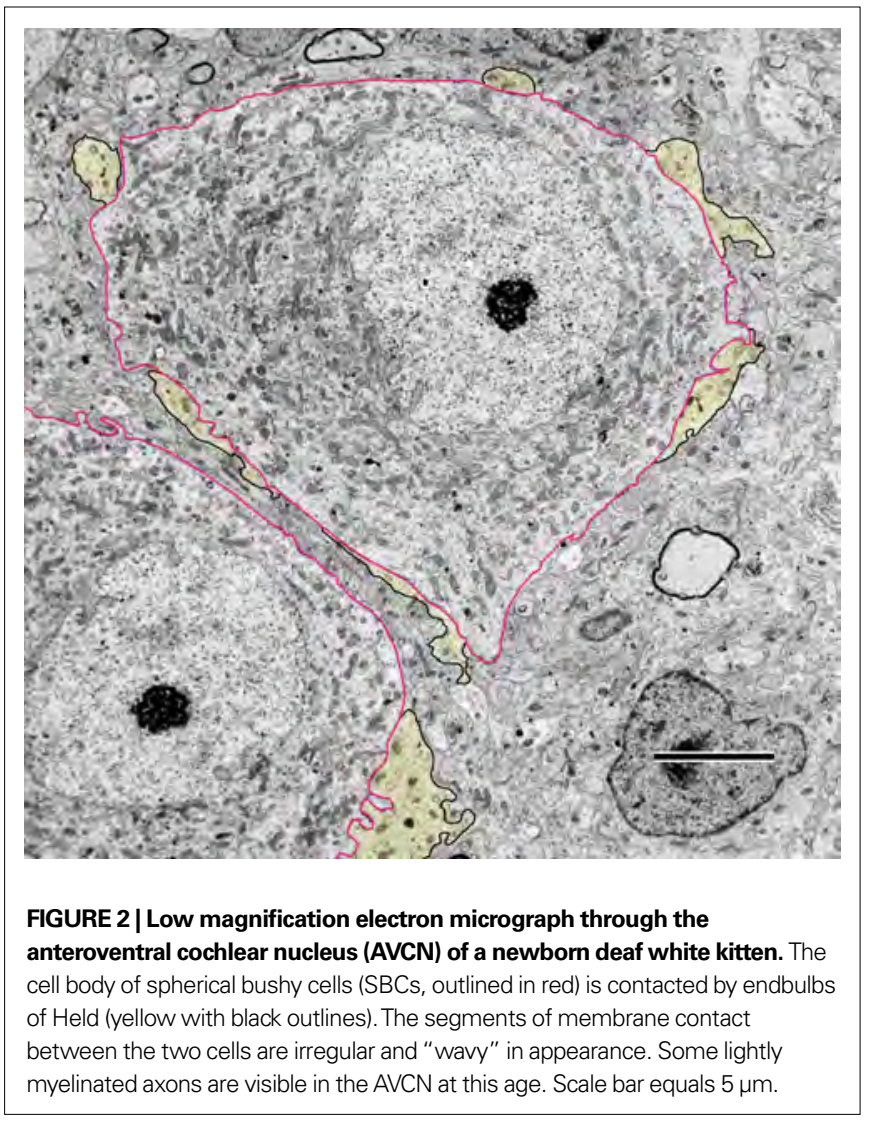

Figure 7B) during the first few days of life. This increase in mitochondrial volume fraction appears linked to the profile reduction as the endbulb branches.

At these early ages, deafness is associated with a decrease in endbulb profile area (Figure 5A) and apposition length (Figure 5B) as compared to normal hearing animals. The interdigitation of membrane between endbulbs and SBCs in deaf animals is reduced as indicated by an apposition form factor approaching one (Figure 5C) and the presence of about half the number of inclusions (Figure 5D). While endings from deaf kittens exhibit fewer than half the number of PSDs as compared to normal endbulbs (Figure 6B), the PSDs they do have are considerably longer (Figure 6C). It is striking that even at the earliest ages, synaptic vesicles are more highly concentrated near PSDs of deaf kittens compared to those of hearing kittens (Figure 7C).

\section{AGES 20 DAYS AND OLDER}

Endbulbs of deaf kittens experience the most profound morphological changes between postnatal days 0 and 20. After 30 days, structural features stabilize (Figures 8,9 and 10). Profile area, apposition length, and apposition complexity plateau and SBC inclusions disappear (Figure 5). An average of two PSDs (Figure 6B) and one punctum adherens (Figure 6A) remain on each endbulb profile. The number of large dense-core vesicles decreases, with an average of fewer than $50 \%$ of endings containing a dense-core vesicle (Figure 7E). PSD length (Figure 6C), mitochondrial volume fraction (Figure 7B), and synaptic vesicle density (Figure 7C) continue to increase into adulthood. 


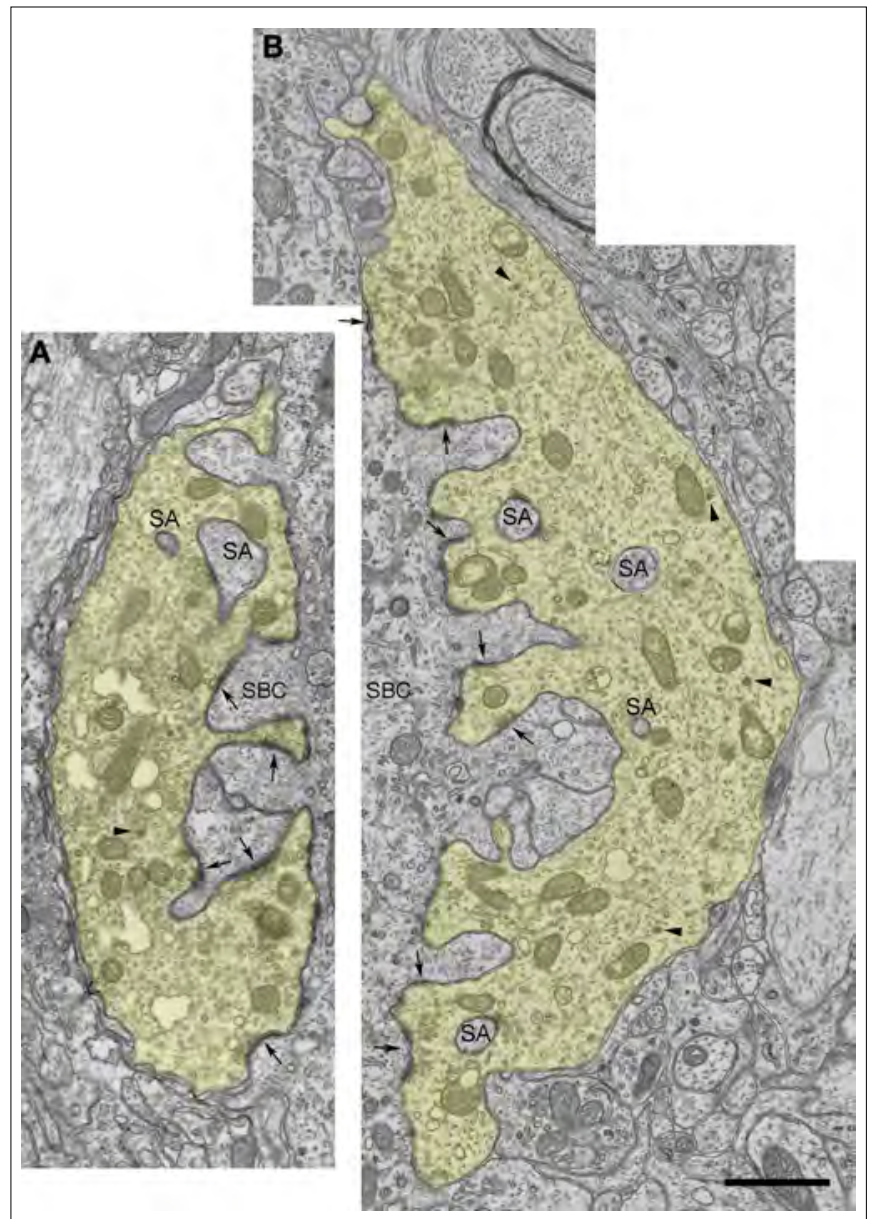

FIGURE 3 | Electron micrographs of endbulbs from a newborn (A) and 5-day old (B) deaf white kitten. (A) The endbulb (yellow) exhibits highly irregular surface contact with the spherical bushy cell (SBC) and contains somatic appendages (SA). Symmetric membrane thickenings mark puncta adherentia; asymmetric membrane thickenings and accumulations of synaptic vesicles mark PSDs (arrows). This newborn white kitten exhibited normal cochlear morphology but was produced by a breeding tom and queen that only give rise to deaf offspring; it had about half the normal number of PSDs in comparison to pigmented kittens, and its PSDs were about $50 \%$ longer than those of newborn pigmented animals. Large dense-core vesicles can be found away from active zones (arrowheads). (B) Electron micrograph of 5-day-old endbulb. This kitten exhibited cochlear pathology and its endbulb morphology was similar to that of a newborn white kitten. Scale bar equals $1 \mu \mathrm{m}$.
Endbulbs of congenitally deaf cats are smaller than normal (Ryugo et al., 1997) so it follows that their profile area would also be smaller (Figure 5A). Although newborn normal animals exhibit more than twice the number of PSDs per profile than deaf, by 30 days the numbers in both cohorts are "pruned" to adult levels, and mature deaf animals exhibit the same number of PSDs as their normal hearing counterparts (Figure 6B). PSD length is greater in deaf animals compared to that of normals throughout development (Figure 6C), but the proportion of the endbulb apposition with SBCs occupied by PSDs was not affected by deafness (Figure 6D).

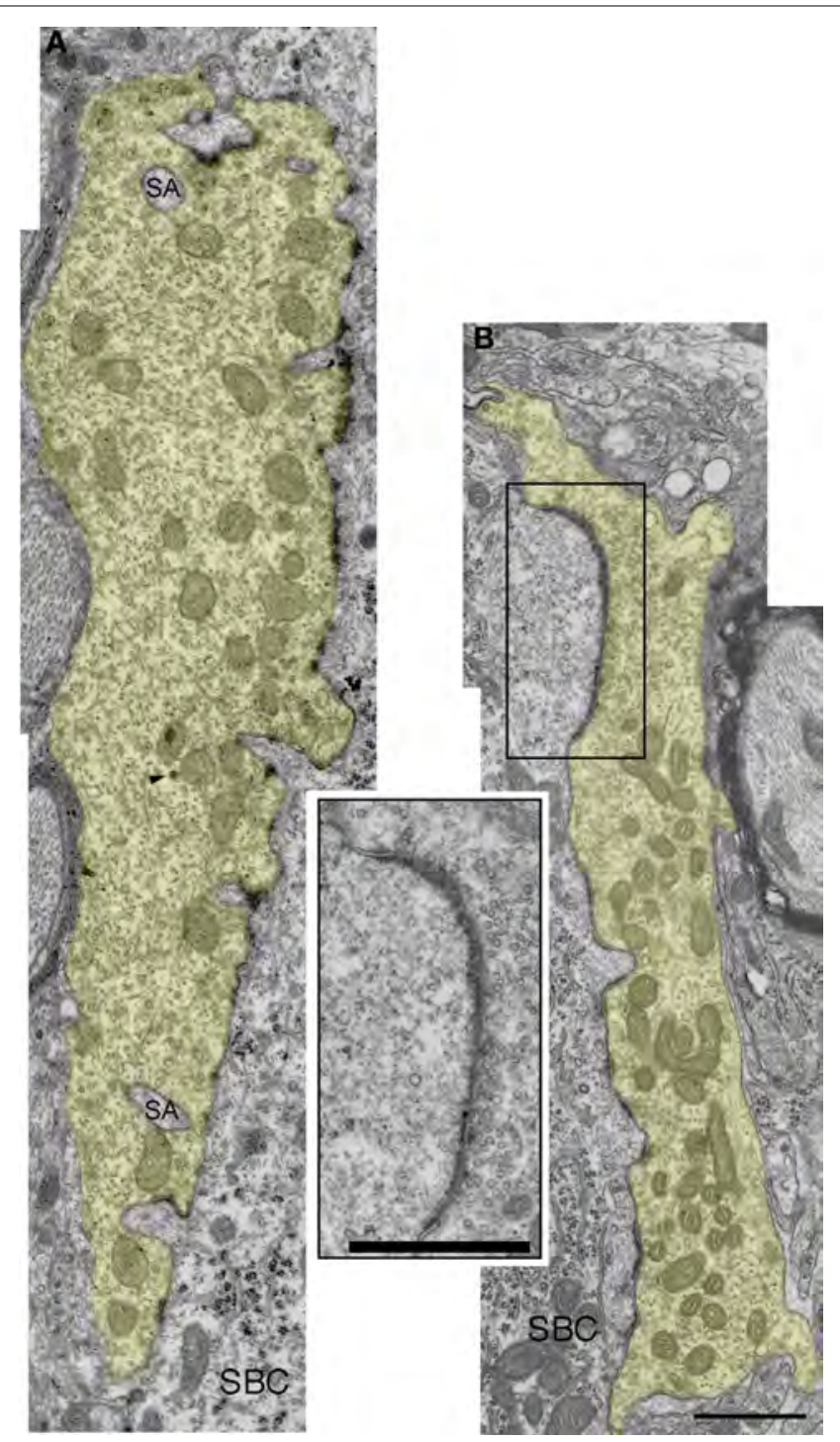

FIGURE 4 | Electron micrographs of endbulbs from a 10-day (A) and 20-day (B) deaf white kitten. (A) The surface between the endbulb (yellow) and SBC membranes has flattened out compared to 0- and 5-day endbulbs and somatic appendages (SA) have decreased. The number of large dense-core vesicles (arrowhead) has also diminished.

(B) Endbulb-SBC surface contact continues to flatten and SBC inclusions have essentially vanished in the 20-day endbulb. PSDs appear as asymmetric membrane thickenings with associated synaptic vesicles. Extremely long, flat PSDs are common in young deaf animals (inset). Scale bars equal $1 \mu \mathrm{m}$.

The PSDs of both normal and deaf cats double in length from birth to adulthood, although the PSDs of deaf animals are consistently larger than those of normals from birth (Figures 8, 9, 10, and 11 ).

Moreover, these PSDs are flattened compared to the dome-shaped structure of PSDs from normal hearing, pigmented cats (Figure 12). In general, more synaptic vesicles are associated with PSDs of deaf compared to hearing cats across all ages (Figures 7C, 11, and 12).

In endings from both normal hearing and deaf cats, the incidence of large dense-core vesicles decreases from about one per profile at birth to become much more rare in older animals (Figure 7E). 


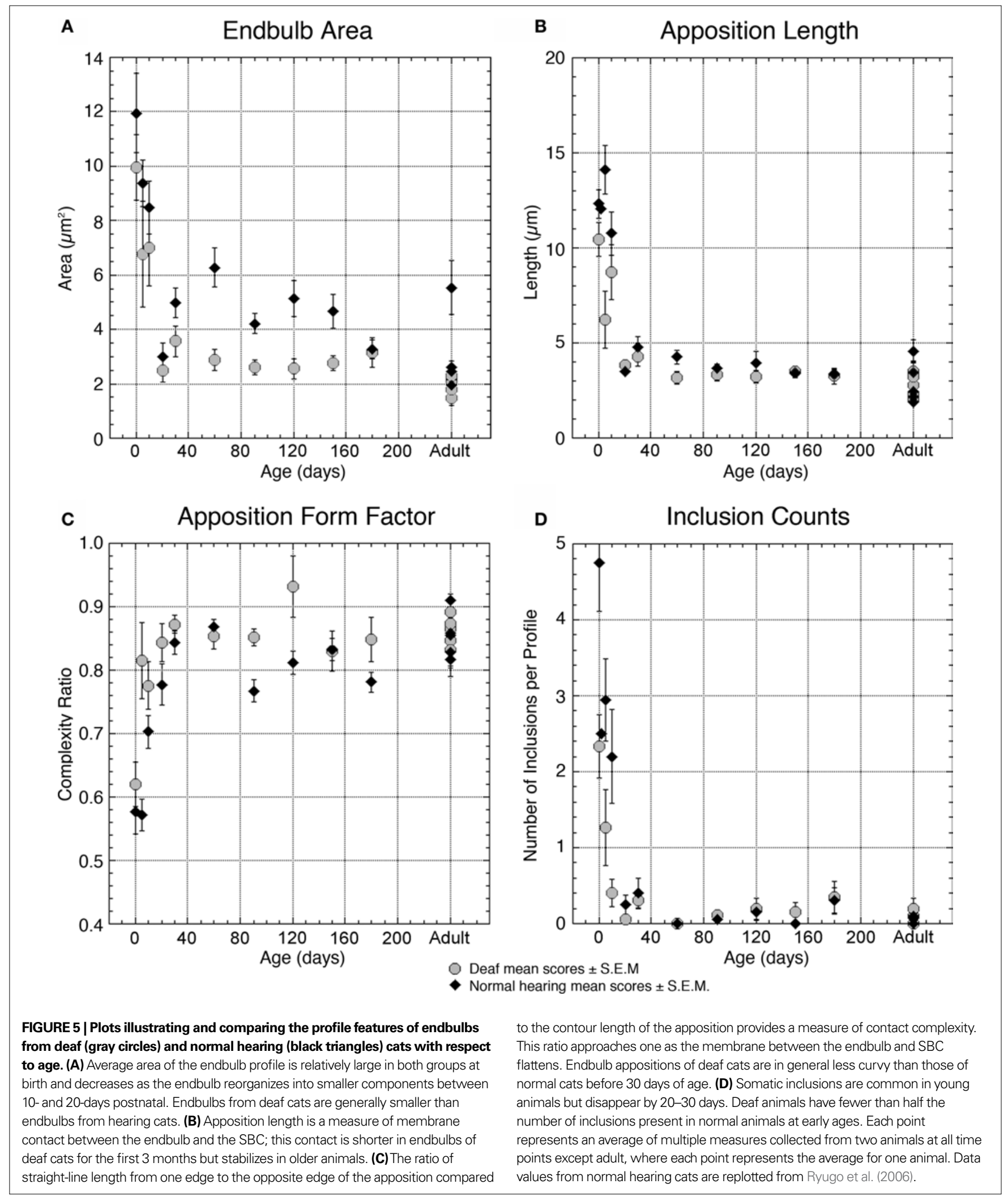

While deaf animals seemed to exhibit greater variability during development, no drastic differences in large dense-core vesicle numbers are seen in deaf compared to normal cats.
Intermembraneous cisternae were first seen at 10-days postnatal in endings from pigmented kittens. Cisternae are created by the appearance of an extracellular space between the pre- and 


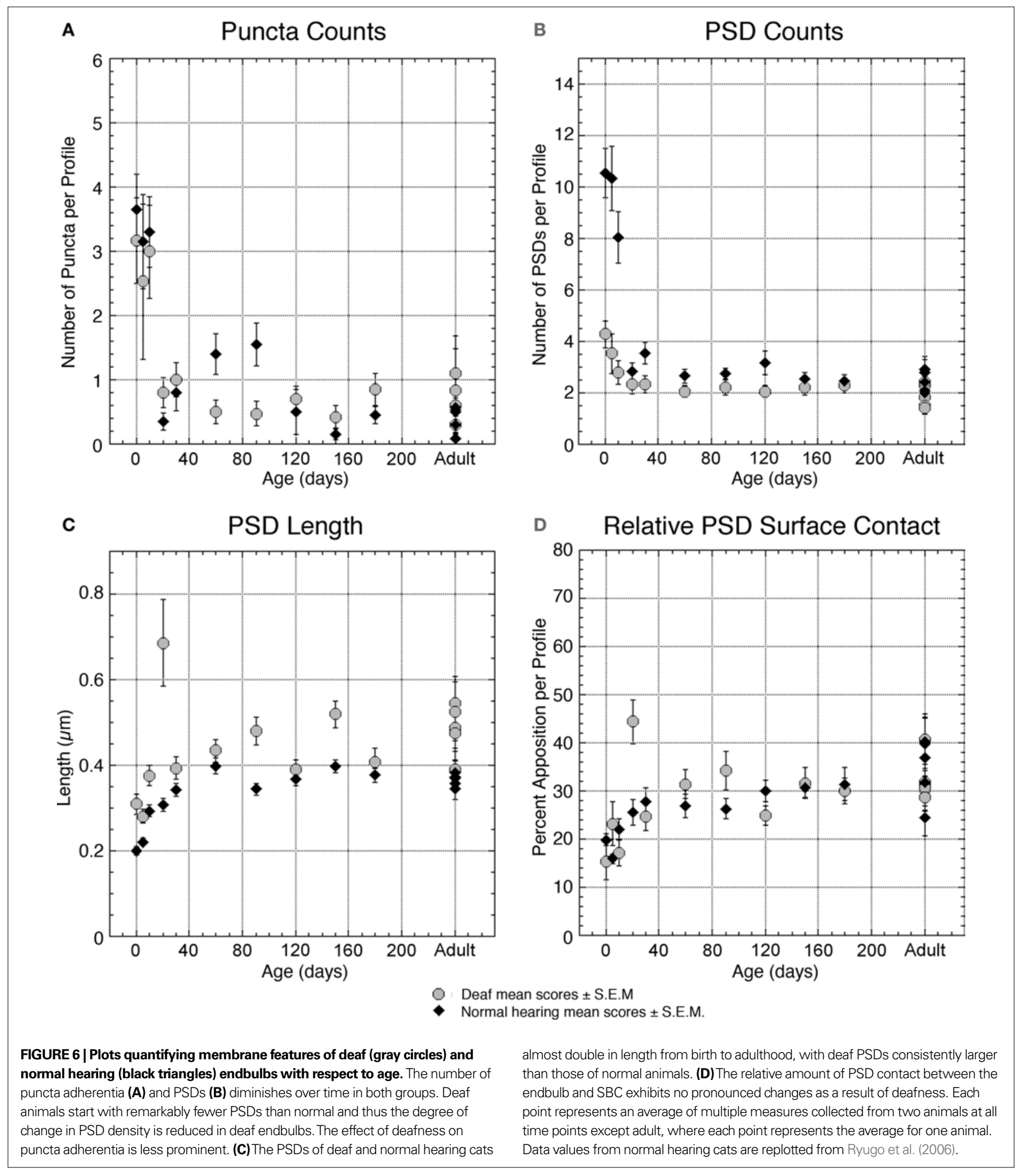

postsynaptic membranes (Figure 13). Frequently, astrocytic processes are seen within the cisternae.

By adulthood, normal hearing animals average one to two cisternae per endbulb profile. Deaf animals, however, do not exhibit cisternae to any notable extent (Figure 7D).

Deafness was found to have no measurable effect on mitochondrial size (Figure 7A) or volume fraction (Figure 7B). The correlation between age and mitochondria size is not significant $(r=0.025, p=0.4)$, whereas that for mitochondria volume fraction is significant $(r=0.49, p<0.05)$. 


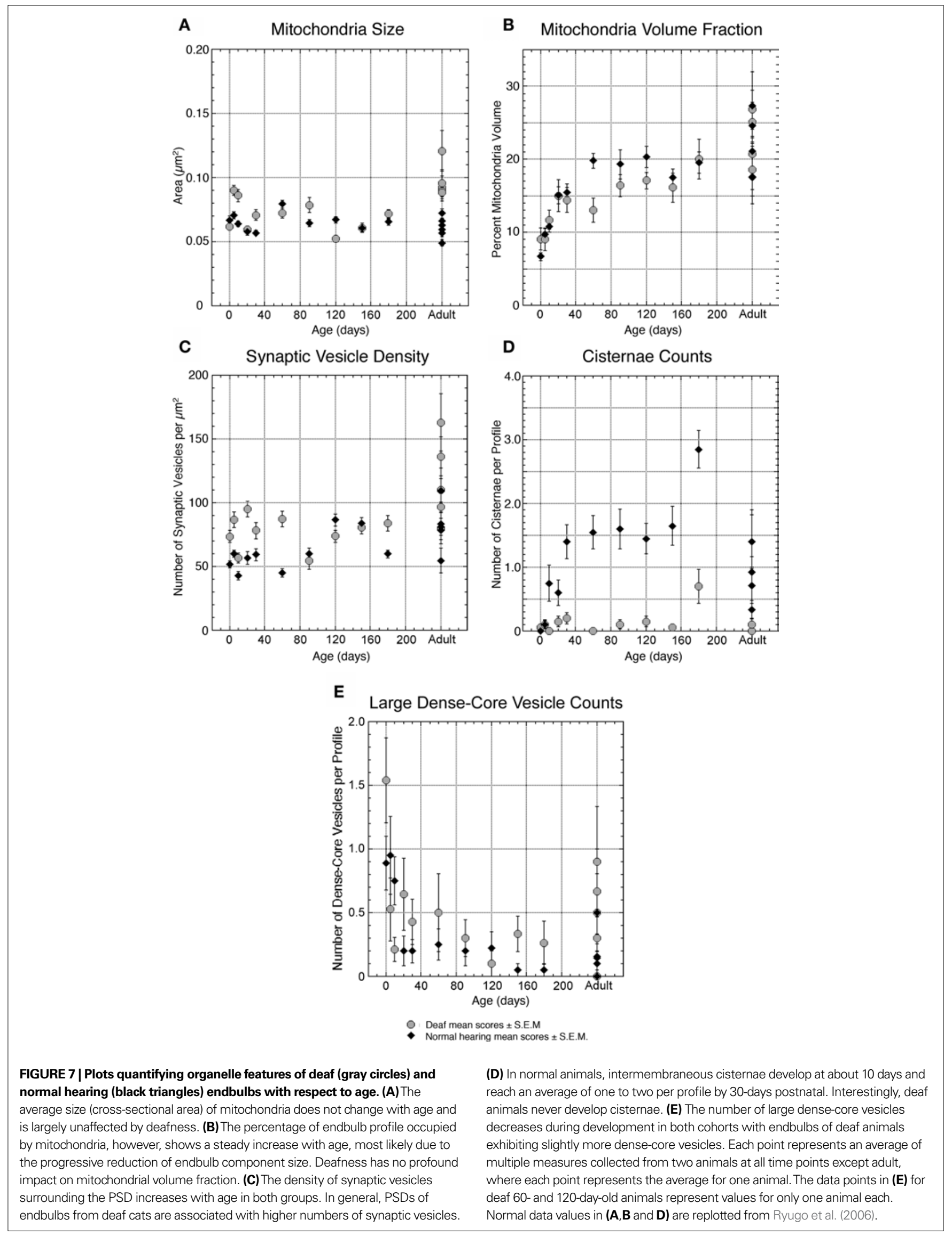




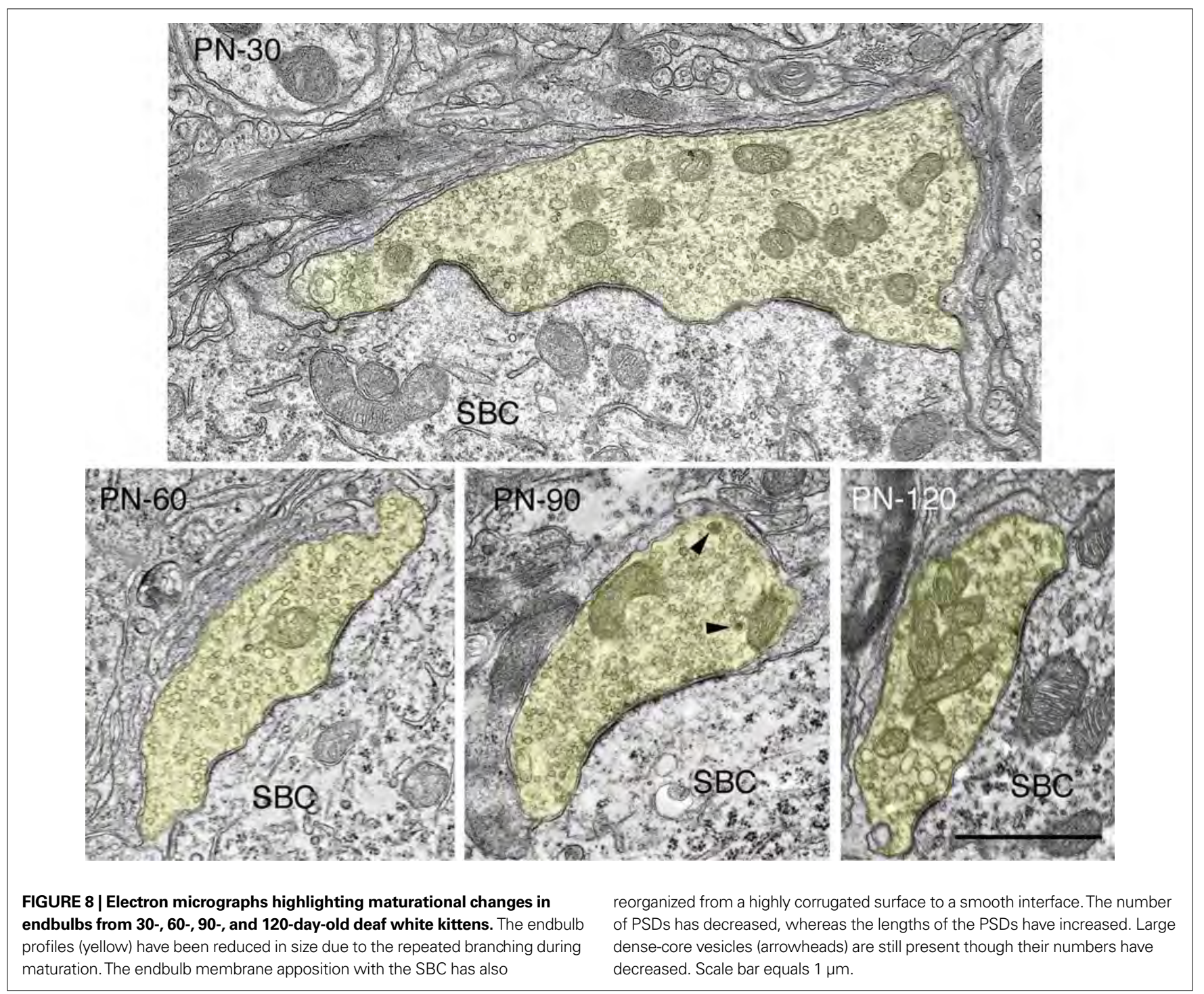

\section{DISCUSSION}

This study describes the structural maturation of the endbulbs of Held of white cats raised from a colony with a history of family deafness. In order to have confidence that these white cats were indeed deaf, we used a light microscope to verify that the cochlear duct was collapsed and that there was no organ of Corti for all cats over five postnatal days of age. Moreover, for cats older than 30 days of age, we also used ABR testing to determine that these cats had no response to clicks or tones up to $100 \mathrm{~dB}$ SPL. In cats younger than 5 days of age, prior to the collapse of the cochlear duct and before we could use ABR methods, we selected kittens from a breeding pair that only produced deaf offspring. Because the morphological features of endbulbs of Held from these newborn kittens were virtually identical to those of one newborn kitten with bilateral spongiform pathology of its inner ear and different from those of newborn pigmented kittens, we infer that the newborn white cats in this study were deaf.

Endbulbs of deaf cats exhibit a smaller profile area, flattened and elongated PSDs, and increased synaptic vesicle density as compared to endbulbs from normal hearing cats (see Figure 14 for summary). These differences are present at birth despite the seemingly intact cochlear structure in both cohorts. Before the onset of hearing, endings from deaf animals have only about half the number of PSDs of normal animals, but by $\mathrm{PN}-20$ both groups show an equal number. One of the most remarkable features of endbulbs in young ( $<30$ days) kittens is the degree of interdigitation with the SBC, as marked by the presence of SBC inclusions and complex endbulb-SBC membrane appositions. In deaf kittens of the same ages, there are fewer inclusions and the membranes are less convoluted. Intermembraneous cisternae begin forming at about PN-10 in normal kittens and by the onset of hearing average one to two per endbulb profile, whereas they are much more rare in deaf kittens. These results show that at birth the endbulbs of Held manifest morphological abnormalities related to deafness despite the normal appearance of the cochlea. In addition, the results also suggest that the development of intermembraneous cisternae is dependent on sound-evoked activity.

\section{COCHLEAR PATHOLOGY}

Deafness in our cat colony is evidenced by two principal types of cochlear pathology, which sometimes combine to produce a third (Ryugo et al., 2003). The first type, involving a spongiform 

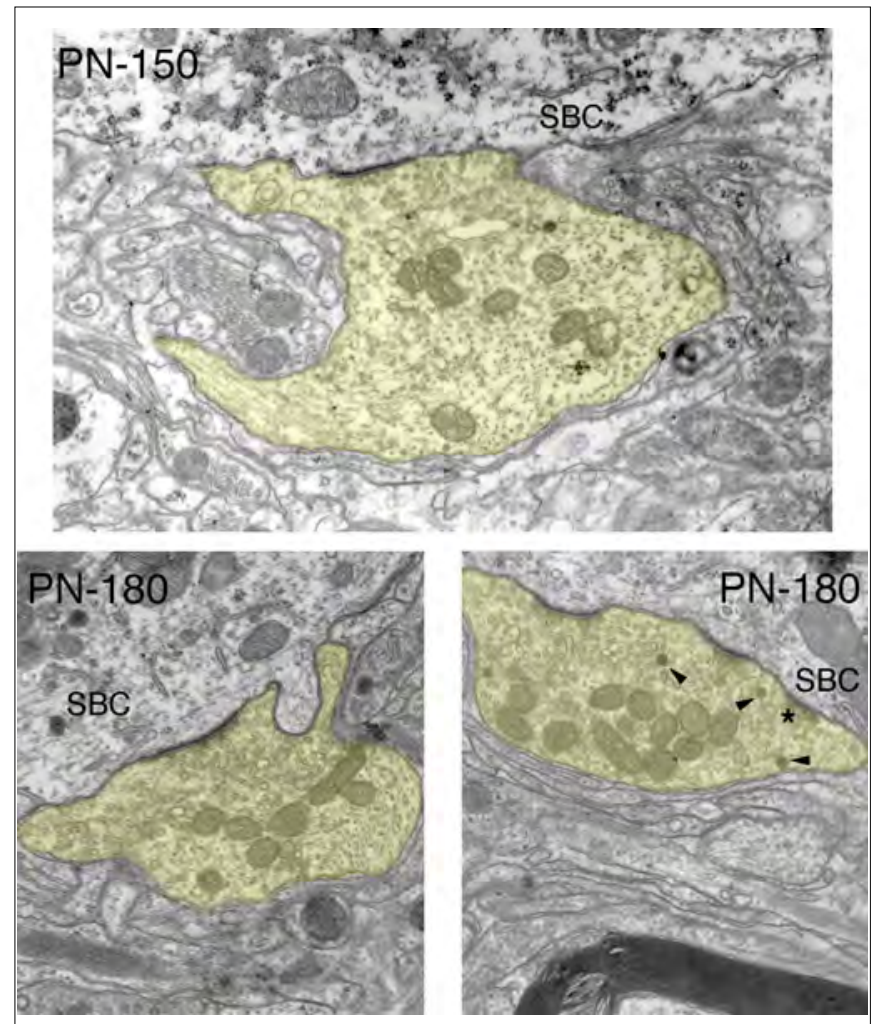

FIGURE 9 | Electron micrographs of endbulbs from 150-day and 180-day deaf white cats. The most prominent and stable morphological features are flattening and lengthening of PSDs, accumulation of synaptic vesicles near the synapses, and increased mitochondrial volume fraction. Smaller, normal looking PSDs $\left({ }^{*}\right)$ are not uncommon in mature deaf animals but they are far outweighed by long flat synapses. Occasionally large dense-core vesicles (arrowheads) can be seen. Scale bar equals $1 \mu \mathrm{m}$.

overgrowth of epithelial tissue, appears to be present at birth. The second, more common cochlear abnormality involves progressive cochlear degeneration and results in the collapse of the scala media and obliteration of the organ of Corti. The scala media collapses between postnatal day 5 and 10 in our deaf white cats, and the development of deafness features of the endbulb do not seem related to this drastic change in the cochlea.

The cochleae of white kittens do not appear different from those of normal pigmented kittens at birth, with inner and outer hair cells intact in both groups. However, endbulbs of animals destined to be deaf exhibit morphological differences on the first day of life. Compared to those of pigmented kittens, endings from deaf white newborn kittens have a smaller endbulb profile area, a shorter and less complex membrane apposition with the SBC, fewer SBC inclusions, and fewer than half the number of PSDs. The PSDs that are present are considerably longer and have a higher concentration of associated synaptic vesicles when compared to normal newborn endings. Endbulb morphology is similar for deaf animals with both types of cochlear deformation. Therefore, the abnormal endbulb morphology in deaf kittens must be caused by some irregularity independent of cochlear structure.

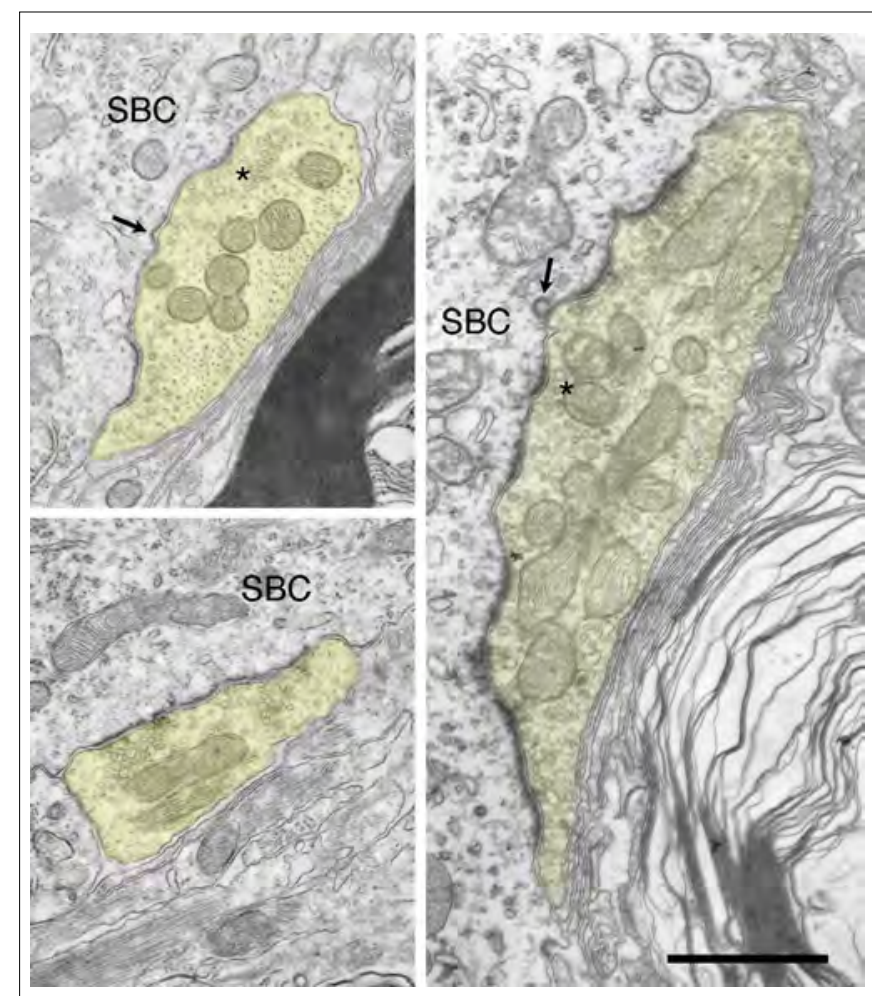

FIGURE 10 | Electron micrographs of endbulbs from adult deaf cats.

These endbulbs typically exhibit a mixture of abnormal synapses characterized by long, flat PSDs and normal (*) ones. Postsynaptic coated vesicles (arrows) at varying stages of endocytosis can infrequently be seen at the SBC-endbulb interface. Scale bar equals $1 \mu \mathrm{m}$.

Cochleae of deafness $(d n / d n)$ mice also appear normal at birth until degeneration starts around postnatal day 10 and progresses until about day 21 (Pujol et al., 1983). Slice recordings revealed abnormally large excitatory postsynaptic currents at the SBCendbulb synapse in deafness mice both before and after hearing onset (Oleskevich and Walmsley, 2002; McKay and Oleskevich, 2007). These authors infer that the difference in synaptic strength between $d n / d n$ and wild type mice is related to the lack of spontaneous activity in the auditory nerve of $d n / d n$ mice. Moreover, an electron microscopic study of newborn cochleae in these mice found abnormal vacuolization in inner hair cells, a swelling of IHC afferent dendrites, and abnormal smooth endoplasmic reticulum in spiral ganglion neurons (Pujol et al., 1983). It is possible that cochleae of newborn deaf white cats also have abnormalities but that they may not be resolvable even at the electron microscope level.

\section{ACTIVITY-DEPENDENCE OF CISTERNAE DEVELOPMENT}

The development of intermembraneous cisternae appears to be dependent on sound-evoked activity. Cisternae start forming in animals destined to develop normal hearing at around PN-10. At this age, the middle ear is opening after having been filled with mesenchyme and occluded by internal ridges since birth (Olmstead and Villablanca, 1980). From this date on, the external ear canal continues to open until about PN-26 (Olmstead and 

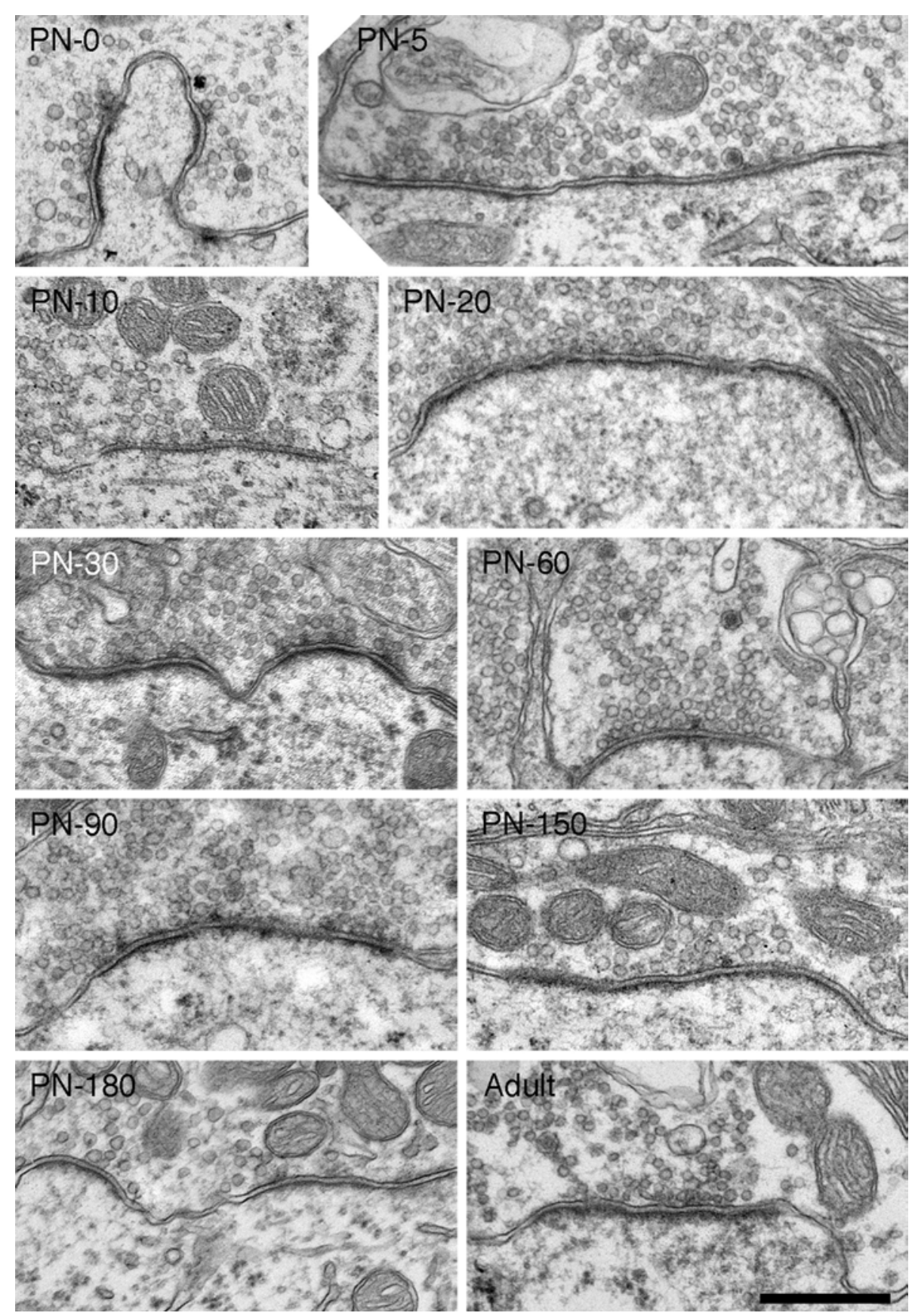

FIGURE 11 | Electron micrographs of synapses from deaf cats. Synapses in deaf animals are marked by long, flat asymmetric membrane thickenings. The presence of small, dome-shaped PSDs is not uncommon in deaf animals, but a large portion of synapses are hypertrophied. From birth, synapses of deaf animals are considerably longer than normals. In fact, PSDs of newborn deaf cats are nearly as large those in mature hearing cats. At all ages, synapses of deaf cats are substantially elongated and flattened compared to those of age-matched hearing animals, including those of hearing littermates. As endbulbs mature, average PSD length grows as does the number of synaptic vesicles associated with synapses. Scale bar equals $0.5 \mu \mathrm{m}$.
Villablanca, 1980; Ryugo et al., 2003). At PN-30, reliable ABRs can be recorded with thresholds that are stable into adulthood (Ryugo et al., 2003). By this age, endbulbs of normal hearing kittens exhibit an average of one to two cisternae per profile. Though cisternae can occasionally be seen in deaf endings, their appearance is rare.
While the exact function of these cisternae is not known, it is speculated that they play a role in transmitter uptake and/or recycling (Ryugo et al., 2006). Often glia, which are known to have high concentrations of glutamate transporters (Gegelashvili and Schousboe, 1997), can be found sending filopodial "fingers" into the cisternae of normal hearing cats. A study of the calyces 

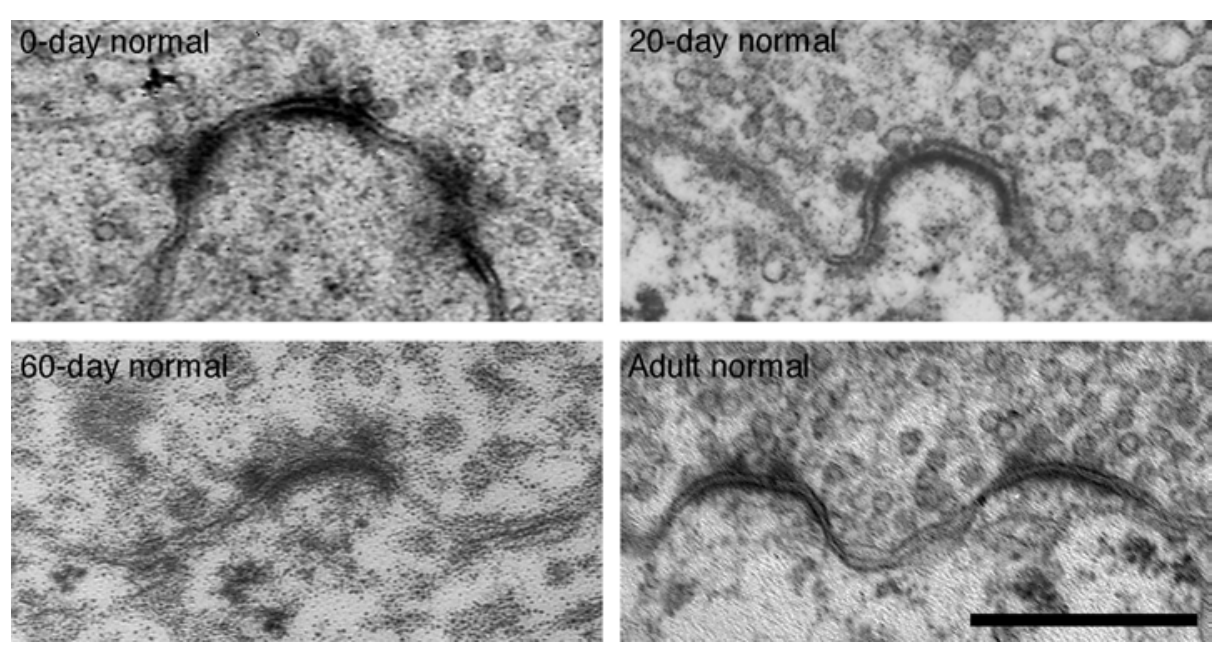

FIGURE 12 | Electron micrographs of 0-day, 20-day, 60-day, and adult synapses of normal hearing cats. PSDs are on average shorter in length and more dome-shaped than those of age-matched deaf animals. Additionally, fewer synaptic vesicles are seen in close proximity to normal synapses. Scale bar equals $0.5 \mu$ m.

of Held in the gerbil found that the calyceal fenestration process allowed glial access to the somata of principal neurons of the medial nucleus of the trapezoid body (MNTB, Ford et al., 2009). In addition, the MNTB neurons having more highly branched calyces, and thus more somatic contact with glia, exhibited a faster decay time and lower residual current in response to a stimulus train. These findings are consistent the idea that glia are involved in transmitter clearance. Therefore, the cisternae that we see between the endbulb and SBC membranes could be extracellular spaces left for glia to enter.

\section{SYNAPSE HYPERTROPHY AND SYNAPTIC VESICLE UPREGULATION}

An increase in PSD size in the endbulbs of deaf animals has been reported in cats (Ryugo et al., 1997, 2005, 2010), Shaker-2 mice (Lee et al., 2003), and rats reared in quiet (Rees et al., 1985).

Slice recordings from congenitally deaf $(d n / d n)$ mice just after hearing onset revealed enhanced synaptic transmission at the endbulb of Held-SBC synapse due to an increase in transmitter release probability (Oleskevich and Walmsley, 2002). The number of independent release sites and the average amplitude of the postsynaptic response to a vesicle of transmitter were no different between deaf and wildtype mice. These findings are consistent with the results presented here. Around the time of hearing onset, endbulbs from deaf kittens have the same number but larger PSDs and a greater accumulation of synaptic vesicles, which may be correlated to a greater glutamate release probability, than normal hearing kittens.

An increase in synaptic strength was also found in deafness $(d n / d n)$ mice before the onset of hearing (McKay and Oleskevich, 2007). In contrast to the presynaptic mechanisms found to underlie these differences in older mice, a postsynaptic mechanism was concluded to be responsible for the increase in synaptic strength in deaf mice before the onset of hearing (i.e., the amplitude of the miniature excitatory postsynaptic currents was larger in deaf mice). The estimated number of release sites and the probability of release were similar in deaf and wildtype mice. Interestingly, there was a trend for the number of release sites in deaf animals to be higher than that of wildtype. It is not clear to what degree morphology can be used to predict synaptic function as measured by quantal analysis, and vice versa, but the physiological results in mice seem to suggest that deafness features of endbulbs may exert varying degrees of effects before and after the age of normal hearing onset.

Cochlear implantation of congenitally deaf white cats resulted in decreased synaptic vesicle density and PSDs that were statistically similar in size to those of normal hearing cats (Ryugo et al., 2005; O'Neil et al., 2010). The finding in the present study that PSDs are larger from birth in kittens destined to become deaf shows that electrical stimulation has a restorative rather than a preventative effect on the endbulb of Held synapse. The determination that these synapses can be rescued by electrical stimulation strongly suggests that their hypertrophy in deaf animals is caused by a lack of auditory nerve activity.

The implication of our analysis is that at birth, synapses of auditory nerve fibers in the cochlear nucleus have already been signaled that they are destined to be abnormal, and that this information is not in the form of obvious cochlear pathology. It is possible that the perinatal harbinger for deafness involves the spontaneous bursting of auditory nerve fibers (Jones et al., 2007; Tritsch et al., 2007). In normal hearing cats and rats, prior to auditory nerve responsiveness to environmental sounds, spontaneous spike discharges occur in repetitive bursting patterns. Because such rhythmic discharges before the onset of vision have been shown to be important for the development of retinotopic projections and binocular vision (McLaughlin and O'Leary, 2005), it is tempting to speculate that spontaneous activity in the auditory nerve serves a similar function. If congenital deafness disrupts and/or prevents the occurrence of such spontaneous discharges, then the absence of auditory nerve spikes would indicate a hearing abnormality that precipitates pathologic change in endbulb synapses. 

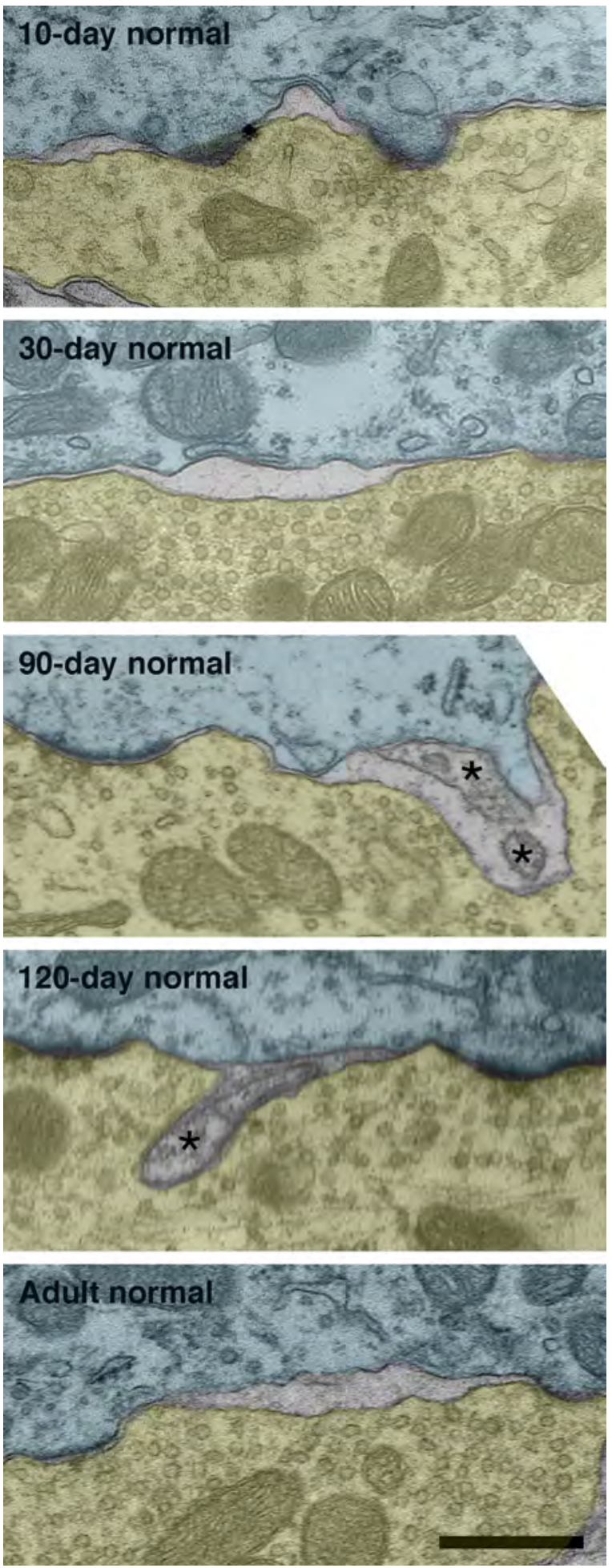

FIGURE 13 | Intermembraneous cisternae in 10-day, 30-day, 90-day,

120-day, and adult normal hearing cats. At around 10-days postnatal, endings of normal hearing kittens start developing spaces between the membranes of SBCs (green) and endbulbs (yellow). These spaces are not artifacts of fixation as surrounding structures are well preserved. Note that cisternae are often found in proximity to PSDs. Occasionally structures (asterisks) can be found occupying the intermembraneous spaces. Scale bar equals $0.5 \mu \mathrm{m}$.

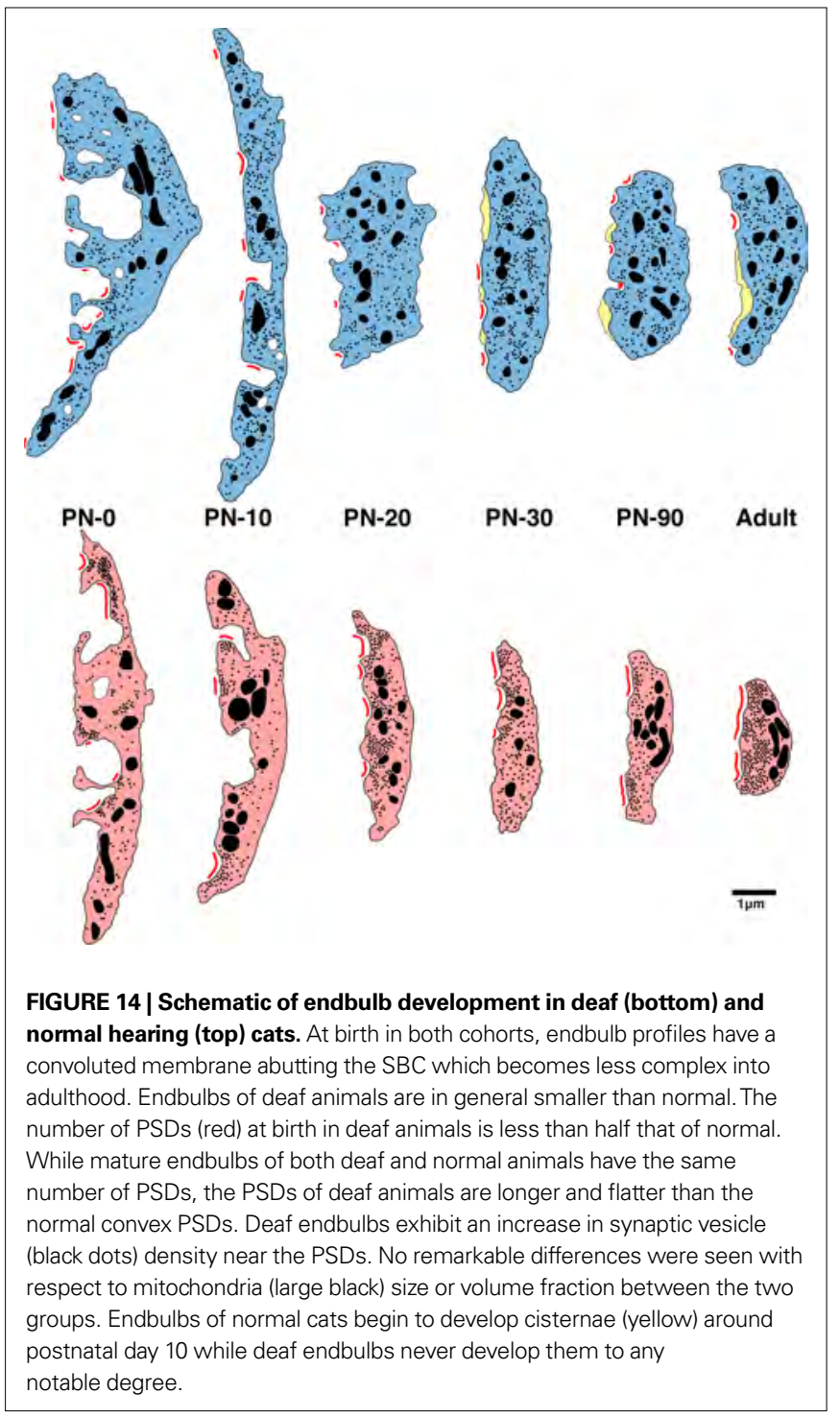

\section{CLINICAL IMPLICATIONS}

We show striking morphological abnormalities at birth in the brain of an animal with hereditary deafness. Cochlear implantation of young ( 3 months of age) deaf kittens resulted in the restoration of endbulb structure, whereas implantation of older (6 months of age) deaf kittens did not (O’Neil et al., 2010). Endbulb pathology, if not corrected early, becomes exacerbated with age. These findings underscore the importance of early intervention in deafness.

\section{ACKNOWLEDGMENTS}

Portions of this work were presented in preliminary form at the 32nd annual MidWinter Meeting of the Association for Research in Otolaryngology, Baltimore, MD, February 14-19, 2009. This work was supported by NIH/NIDCD grants DC000232, DC005211, EY01765; The Emma Liepmann Endowment Fund; and a grant from the Advanced Bionics Corporation. 


\section{REFERENCES}

Bosher, S. K., and Hallpike, C. S. (1965). Observations on the histological features, development, and pathogenesis of the inner ear degeneration of the deaf white cat. Proc. R. Soc. Lond., B, Biol. Sci. 162, 147-170.

Bosher, S. K., and Hallpike, C. S. (1967). Observations on the histogenesis of the inner ear degeneration of the deaf white cat and its possible relationship to the aetiology of certain unexplained varieties of human congenital deafness. J. Laryngol. Otol. 80, 222-235.

Brighton, P., Ramesar, R., and Winship, I. (1991). Hearing impairment and pigmentary disturbance. Ann. N. Y. Acad. Sci. 630, 152-166.

Carr, C. E., and Konishi, M. (1990). A circuit for detection of interaural time differences in the brain stem of the barn owl. J. Neurosci. 10, 3227-3246.

Deol, M. S. (1970). The relationship between abnormalities of pigmentation and of the inner ear. Proc. R. Soc. Lond., B, Biol. Sci. 175, 201-217.

Ford, M. C., Grothe, B., and Klug, A. (2009). Fenestration of the calyx of Held occurs sequentially along the tonotopic axis, is influenced by afferent activity, and facilitates glutamate clearance. J. Comp. Neurol. 514, 92-106.

Gegelashvili, G., and Schousboe,A. (1997). High affinity glutamate transporters: regulation of expression and activity. Mol. Pharmacol. 52, 6-15.

Jones, T. A., Leake, P. A., Snyder, R. L., Stakhovskaya, O., and Bonham, B. (2007). Spontaneous discharge patterns in cochlear spiral ganglion cells before the onset of hearing in cats. J. Neurophysiol. 98, 1898-1908.

Koppl, C. (1994). Auditory nerve terminals in the cochlear nucleus magnocellularis: differences between low and high frequencies. J. Comp. Neurol.339, 438-446.

Koppl, C., and Carr, C. E. (1997). Lowfrequency pathway in the barn owl's auditory brainstem. J. Comp. Neurol. 378, 265-282.
Lee, D. J., Cahill, H. B., and Ryugo, D. K. (2003). Effects of congenital deafness in the cochlear nuclei of Shaker-2 mice: an ultrastructural analysis of synapse morphology in the endbulbs of Held. J. Neurocytol. 32, 229-243.

Limb, C. J., and Ryugo, D. K. (2000). Development of primary axosomatic endings in the anteroventral cochlear nucleus of mice. J. Assoc. Res. Otolaryngol. 1, 103-119.

Mair, I. W. (1973). Hereditary deafness in the white cat. Acta Otolaryngol. Suppl. 314, 1-48.

McKay, S. M., and Oleskevich, S. (2007). The role of spontaneous activity in development of the endbulb of Held synapse. Hear. Res. 230, 53-63.

McLaughlin, T., and O'Leary, D. D. (2005). Molecular gradients and development of retinotopic maps. Annu. Rev. Neurosci. 28, 327-355.

Molnar, C. E., and Pfeiffer, R. R. (1968). Interpretation of spontaneous spike discharge patterns of neurons in the cochlear nucleus. Proc. IEEE 56, 993-1004.

Murthy, V. N., Schikorski, T., Stevens, C. F., and Zhu, Y. (2001). Inactivity produces increases in neurotransmitter release and synapse size. Neuron 32, 673-682.

Oleskevich, S., and Walmsley, B. (2002). Synaptic transmission in the auditory brainstem of normal and congenitally deaf mice. J. Physiol. (Lond.) 540, 447-455.

Olmstead, C. E., and Villablanca, J. R. (1980). Development of behavioral audition in the kitten. Physiol. Behav. 24, 705-712.

O’Neil, J. N., Limb, C. J., Baker, C. A., and Ryugo, D. K. (2010). Bilateral effects of unilateral cochlear implantation in congenitally deaf cats. J. Comp. Neurol. (in press)

Pfeiffer, R.R. (1966a). Anteroventral cochlear nucleus: wave forms of extracellularly recorded spike potentials. Science 154, 667-668.

Pfeiffer, R. R. (1966b). Classification of response patterns of spike discharges for units in the cochlear nucleus: tone- burst stimulation. Exp. Brain Res. 1, 220-235.

Pujol, R., Shnerson, A., Lenoir, M., and Deol, M.S. (1983). Early degeneration of sensory and ganglion cells in the inner ear of mice with uncomplicated genetic deafness $(\mathrm{dn})$ : preliminary observations. Hear. Res. 12, 57-63.

Rees, S., Galdner, F. H., and Aitkin, L. (1985). Activity dependent plasticity of postsynaptic density structure in the ventral cochlear nucleus of the rat. Brain Res. 325, 370-374.

Ryugo, D. K., Baker, C. A., Montey, K. L., Chang, L. Y., Coco, A., Fallon, J. B., Shepherd, R. K. (2010). Synaptic plasticity after chemical deafening and electrical stimulation of the auditory nerve in cats. J. Comp. Neurol. in press.

Ryugo, D. K., Cahill, H. B., Rose, L. S., Rosenbaum, B. T., Schroeder, M. E., and Wright, A. L. (2003). Separate forms of pathology in the cochlea of congenitally deaf white cats. Hear. Res. 181, 73-84.

Ryugo, D. K., and Fekete, D. M. (1982) Morphology of primary axosomatic endings in the anteroventral cochlear nucleus of the cat: a study of the endbulbs of Held. J. Comp. Neurol. 210, 239-257.

Ryugo, D. K., Kretzmer, E.A., and Niparko, J. K. (2005). Restoration of auditory nerve synapses in cats by cochlear implants. Science 310, 1490-1492.

Ryugo, D. K., Montey, K. L., Wright, A. L., Bennett, M. L., and Pongstaporn, T. (2006). Postnatal development of a large auditory nerve terminal: the endbulb of Held in cats. Hear. Res. 216-217, 100-115.

Ryugo, D. K., Pongstaporn, T., Huchton, D. M., and Niparko, J. K. (1997). Ultrastructural analysis of primary endings in deaf white cats: morphologic alterations in endbulbs of Held. J. Comp. Neurol. 385, 230-244.

Ryugo, D. K., Rosenbaum, B. T., Kim, P. J., Niparko, J. K., and Saada, A. A. (1998). Single unit recordings in the auditory nerve of congenitally deaf white cats: morphological correlates in the cochlea and cochlear nucleus. J. Comp. Neurol. 397, 532-548.

Scheibe,A. (1892). A case of deaf-mutism, with auditory atrophy and anomalies of development in the membranous labyrinth of both ears. J. Comp. Neurol. 397, 532-548.

Scheibe, A. (1895). Bildungsanomalien im hautigen Labyrinth bei Taubstummheit. Z Ohrenheilkd 27, 95-99.

Smith, P. H., Joris, P. X., and Yin, T. C. (1993). Projections of the physiologically characterized spherical bushy cell axons from the cochlear nucleus of the cat: evidence for delay lines to the medial superior olive.J. Comp. Neurol. 331, 245-260.

Suga, F., and Hattler, K. W. (1970). Physiological and histopathological correlates of hereditary deafness in animals. Laryngoscope 80, 81-104.

Tritsch, N. X., Yi, E., Gale, J. E., Glowatzki, E., and Bergles, D. E. (2007). The origin of spontaneous activity in the developing auditory system. Nature 450, 50-55.

Conflict of Interest Statement: The authors declare that the research was conducted in the absence of any commercial or financial relationships that could be construed as a potential conflict of interest.

Received: 14 January 2010; paper pending published: 15 February 2010; accepted: 24 April 2010; published online: 21 May 2010.

Citation:BakerCA,MonteyKL, Pongstaporn T and Ryugo DK (2010) Postnatal development of the endbulb of Held in congenitally deaf cats. Front. Neuroanat. 4:19. doi: 10.3389/fnana.2010.00019

Copyright (c) 2010 Baker, Montey, Pongstaporn and Ryugo. This is an openaccess article subject to an exclusive license agreement between the authors and the Frontiers Research Foundation, which permits unrestricted use, distribution, and reproduction in any medium, provided the original authors and source are credited. 